\section{Comparison of MS score and HScore for the diagnosis of adult-onset Still's disease- associated macrophage activation syndrome}

We read with great interest the article by Minoia et al, ${ }^{1}$ which reported MAS/sJIA (MS) score, a new scoring tool for diagnosis of systemic juvenile idiopathic arthritis (sJIA)-associated macrophage activation syndrome (MAS). This new diagnostic score has raised great interest and also some concerns..$^{2-5}$ Although Wang $e t a l^{2}$ tested the MS score in a group of Chinese patients with adult-onset Still's disease (AOSD)-associated MAS, the diagnostic capacity needs to be evaluated in future.

HScore was first developed for the diagnosis of reactive haemophagocytic syndrome, which resulted from mainly haematological malignancy or infection, ${ }^{6}$ and was ever tested in patients with MAS, which resulted from different rheumatic diseases, with good performance. ${ }^{7}$ Since there are no studies comparing the diagnostic capability of HScore and MS score, we conducted a study to compare the capacity of HScore and MS score for the diagnosis of AOSD-associated MAS.

Patients diagnosed with AOSD during January 2012 and October 2019 in our hospital were retrospectively analysed. As there is no gold standard for diagnosing AOSD-associated MAS, the diagnosis of MAS is mainly based on the profiles of clinical and laboratory data as well as agreement of more than four rheumatologists.

We included 174 patients with pure AOSD and 35 patients with AOSD-associated MAS. Clinical and laboratory data of these two groups of patients are detailed in table 1. Patients with AOSD-associated MAS were younger than those with pure AOSD $(32 \pm 11.4$ years vs $36.9 \pm 13.5$ years, $\mathrm{p}=0.028)$. More deaths were observed among patients with AOSD-associated MAS ( $17.1 \%$ vs $3.4 \%, p=0.001)$. Regarding clinical manifestations, patients with AOSD-associated MAS had higher incidence of central nervous system involvement, decreased blood cells, haemorrhagic manifestations, hepatomegaly and enlarged lymph nodes $(\mathrm{p}<0.05)$, but comparable incidence of arthritis, eruption and abnormal liver function, compared with patients with pure AOSD. As for laboratory tests, patients with AOSD-associated MAS had a relatively lower level of white blood cell count, neutrophil count, lymphocyte count, platelet count, haemoglobin, fibrinogen and erythrocyte sedimentation rate $(p<0.05)$ and a relatively higher level of ferritin, triglycerides and liver enzyme $(\mathrm{p}<0.05)$.

Patients with AOSD-associated MAS had higher HScore and MS score than those with pure AOSD (table 1). ROC curve analysis (figure 1) revealed that the HScore had a stronger ability to diagnose AOSD-associated MAS compared with MScore (AUC $=0.973$ and 0.865 for HScore and MS score, respectively; $\mathrm{p}<0.001$ ). HScore of $\geq 120$ performed best (sensitivity $90.6 \%$ and specificity $89.6 \%$ ), while MS score of $\geq-0.25$ performed best and yielded a sensitivity of $75 \%$ and a specificity of $73 \%$.

Our results indicate that patients with AOSD-associated MAS had higher incidence of visceral involvement and more severe disease than patients with pure AOSD, and HScore seems to perform much better than MS score for the diagnosis of AOSDassociated MAS. MS score was tested by Wang $e t a l^{2}$ that it is suitable to detect MAS in patients with AOSD; however, its cut-off value should be modified from $\geq-2.1$ to $\geq-1.08$ and yielded a sensitivity of $94.1 \%$ and a specificity of $95.0 \%$. The different performance of MS score in AOSD may result from different patients' selection. The diagnosis of MAS by Wang et

\begin{tabular}{|c|c|c|c|}
\hline & non-MAS ( $n=174)$ & MAS $(n=35)$ & $P$ values \\
\hline \multicolumn{4}{|l|}{ Demographic } \\
\hline Age, mean $\pm S D$ (years) & $36.9 \pm 13.5$ & $32 \pm 11.4$ & 0.028 \\
\hline Gender (F/M) & $138 / 36$ & $28 / 7$ & 0.927 \\
\hline Deaths, n (\%) & $6(3.4)$ & $6(17.1)$ & 0.001 \\
\hline \multicolumn{4}{|l|}{ Clinical manifestations } \\
\hline Arthritis, n (\%) & 119 (68.4) & $25(71.4)$ & 0.723 \\
\hline Eruption, $\mathrm{n}(\%)$ & $123(70.7)$ & $28(80)$ & 0.262 \\
\hline Abnormal liver function, $\mathrm{n}(\%)$ & $143(82.2)$ & $33(94.3)$ & 0.073 \\
\hline Decreased blood cells, n (\%) & $1(0.6)$ & $26(74.3)$ & $<0.001$ \\
\hline Central nervous system involvement, $\mathrm{n}(\%)$ & $0(0)$ & $7(20)$ & $<0.001$ \\
\hline Haemorrhagic manifestations, $n(\%)$ & $0(0)$ & $6(17.1)$ & $<0.001$ \\
\hline Splenomegaly, $\mathrm{n}(\%)$ & $36(20.7)$ & $8(22.9)$ & 0.774 \\
\hline Hepatomegaly, n (\%) & $3(1.7)$ & $4(11.4)$ & 0.016 \\
\hline Enlarged lymph nodes, n (\%) & $107(61.5)$ & $28(80)$ & 0.037 \\
\hline Known underlying immunosuppression & $1(0.6)$ & $13(37.1)$ & $<0.001$ \\
\hline \multicolumn{4}{|l|}{ Temperature $\left({ }^{\circ} \mathrm{C}\right)$} \\
\hline $38.4-39.4$ & $51(29.3)$ & $3(8.6)$ & 0.011 \\
\hline$>39.4$ & $123(70.7)$ & $32(91.4)$ & 0.011 \\
\hline Bone marrow Hemophagocytosis & $1(0.6)$ & $17(48.6)$ & $<0.001$ \\
\hline \multicolumn{4}{|l|}{ Laboratory features } \\
\hline White cell count $\left(\times 10^{9} / L\right)$ & $14.2(3.6-50.4)$ & $6.3(0.2-37.7)$ & $<0.001$ \\
\hline Neutrophil count $\left(\times 10^{9} / \mathrm{L}\right)$ & $12.1(1.13-48.13)$ & $5.2(0-36.3)$ & $<0.001$ \\
\hline Lymphocyte count $\left(\times 10^{9} / \mathrm{L}\right)$ & $1.28(0.4-4.71)$ & $0.7(0.15-3.08)$ & $<0.001$ \\
\hline Haemoglobin $(g / L)$ & $109(53-141)$ & $85(63-134)$ & $<0.001$ \\
\hline Platelet count $\left(\times 10^{9} / \mathrm{L}\right)$ & $295(34-564)$ & $81(8-368)$ & $<0.001$ \\
\hline Ferritin (ng/mL) & $1813(25-42$ 138) & 2000 (459-217988) & 0.007 \\
\hline Aspartate aminotransferase (U/L) & $40(7-555)$ & $157(17-2888)$ & $<0.001$ \\
\hline Alanine aminotransferase (U/L) & $37(5-539)$ & $143(11-2407)$ & $<0.001$ \\
\hline Triglycerides (mmol/L) & $1.2(0.4-3.8)$ & $2.56(0.7-19.3)$ & $<0.001$ \\
\hline Fibrinogen (g/L) & $4.3(0.9-8.1)$ & $1.49(0.31-5.59)$ & $<0.001$ \\
\hline ESR (mm/hour) & $69(3-132)$ & $27(1-126)$ & $<0.001$ \\
\hline CRP (mg/L) & $83.0(0.27-498.9)$ & $75.6(1.5-250)$ & 0.772 \\
\hline \multicolumn{4}{|l|}{ Scores } \\
\hline HScore, median (range) & $68(33-156)$ & $196(98-333)$ & $<0.001$ \\
\hline MS score, median (range) & $-1.17(-1.26$ to 2.52$)$ & $1.05(-1.26$ to 26.55$)$ & $<0.001$ \\
\hline
\end{tabular}

$a l^{2}$ was mainly based on the 2004 haemophagocytic lymphohistiocytosis (HLH-2004) diagnostic criteria, which is not suitable for early recognition of MAS, ${ }^{8}$ indicating that the patients with MAS in Wang et al's study might be in a relatively late stage. We believe that we included patients with MAS in a much earlier stage.

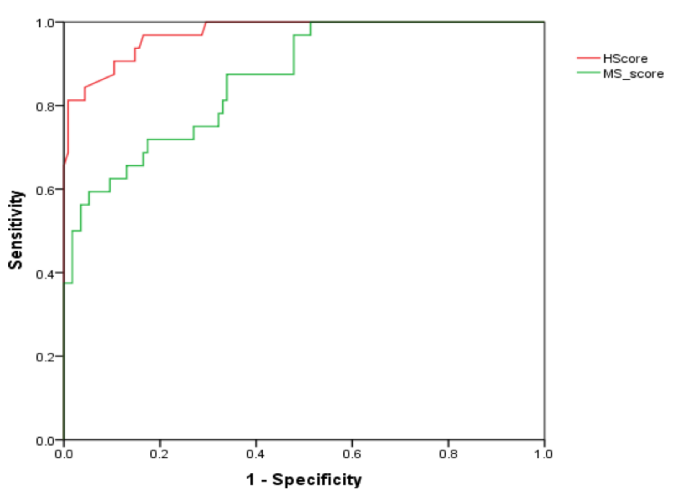

Figure 1 Roc curve of HScore and MS score. HScore $=120$, sensitivity $=90.6 \%$, specificity $=89.6 \%$. MS score $=-0.45$, sensitivity $=75 \%$, specificity $=73 \%$. AUC-HScore $=0.973$, AUC-MS score $=0.865, p<0.001$ 
The best cut-off value of HScore was 169 , with a sensitivity of $93 \%$ and a specificity of $86 \%$ when it was developed. ${ }^{6}$ The cutoff was set at 190.5 and yielded a sensitivity of $96.7 \%$ and a specificity of $98.4 \%$ when tested in a group of Turkish patients with MAS. $^{7}$ Our results indicate that HScore is suitable for detecting AOSD-MAS but with a lower cut-off value. Indeed, different patients' selection criteria, different disease status and different underlying diseases may result in quite different conclusions. Further studies are needed to validate these different scoring tools.

\section{Lei Zhang ๑ , Xiaopei Yang, Tian-Fang Li, Xiaojun Liu, Shengyun Liu}

Rheumatology Department, Zhengzhou University First Affiliated Hospital, Zhengzhou, Henan, China

Correspondence to Shengyun Liu, Rheumatology, Zhengzhou University First Affiliated Hospital, Zhengzhou 450052, China; fccliusy2@zzu.edu.cn

Correction notice This article has been corrected since it published Online First. Table 1 has been amended.

Acknowledgements We thank our colleagues for their assistance in data collection and analysis.

Contributors $L Z$ and $T L$ designed the study; $L Z, X Y$ and $X L$ collected the data; $L Z$ analysed the data, performed statistical analysis and wrote the manuscript; $T L$ and $S L$ revised the manuscript. All authors read and approved the final manuscript.

Funding The authors have not declared a specific grant for this research from any funding agency in the public, commercial or not-for-profit sectors.

Competing interests None declared.

Patient and public involvement Patients and/or the public were not involved in the design, conduct, reporting or dissemination plans of this research.

Patient consent for publication Not required.

Provenance and peer review Not commissioned; internally peer reviewed.

(C) Author(s) (or their employer(s)) 2020. No commercial re-use. See rights and permissions. Published by BMJ.

A Check for updates
To cite Zhang L, Yang X, Li T-F, et al. Ann Rheum Dis Epub ahead of print: [please include Day Month Year]. doi:10.1136/annrheumdis-2020-217917

Received 12 May 2020

Accepted 15 May 2020

\section{Sinked}

http://dx.doi.org/10.1136/annrheumdis-2020-218033

Ann Rheum Dis 2020;0:1-2. doi:10.1136/annrheumdis-2020-217917

ORCID iD

Lei Zhang http://orcid.org/0000-0003-4105-0824

\section{REFERENCES}

1 Minoia F, Bovis F, Davi S, et al. Development and initial validation of the MS score for diagnosis of macrophage activation syndrome in systemic juvenile idiopathic arthritis. Ann Rheum Dis 2019;78:1357-62.

2 Wang R, Li T, Ye S, et al. Application of MS score in macrophage activation syndrome patients associated with adult onset still's disease. Ann Rheum Dis 2019:annrheumdis-2019-216286.

3 Chi H, Wang Z, Yang C, et al. Ms score in systemic juvenile idiopathic arthritis: suitable for routine use? Ann Rheum Dis 2019:annrheumdis-2019-216041.

4 Minoia F, Ravelli A. Adapting the MS score for detection of macrophage activation syndrome in adult-onset Still's disease. Response to 'Application of MS score in macrophage activation syndrome patients associated with adult onset Still's disease' by Wang et al. Ann Rheum Dis 2019:annrheumdis-2019-216310.

5 Minoia F, Ravelli A. Fostering the application of the MS score in systemic juvenile idiopathic arthritis. Response to: 'MS score in systemic juvenile idiopathic arthritis: suitable for routine use?' by Chi et al. Ann Rheum Dis 2019:annrheumdis-2019-216067.

6 Fardet L, Galicier L, Lambotte O, et al. Development and validation of the HScore, a score for the diagnosis of reactive hemophagocytic syndrome. Arthritis Rheumatol 2014;66:2613-20

7 Batu ED, Erden A, Seyhoğlu E, et al. Assessment of the HScore for reactive haemophagocytic syndrome in patients with rheumatic diseases. Scand I Rheumatol 2017:46:44-8.

8 Crayne CB, Albeituni S, Nichols KE, et al. The immunology of macrophage activation syndrome. Front Immunol 2019;10:119. 